\title{
The Assessment of Construction Project Risks with the Use of Fuzzy Delphi Methodology- Case Study Photovoltaic Project in Greece
}

\author{
Odysseas Manoliadis \\ Department of Civil Engineering, Democritus University of Thrace, Xanthi, Greece
}

Email address:

omanolia@civil.duth.gr

To cite this article:

Odysseas Manoliadis. The Assessment of Construction Project Risks with the Use of Fuzzy Delphi Methodology- Case Study Photovoltaic Project in Greece. International Journal of Management and Fuzzy Systems. Vol. 4, No. 1, 2018, pp. 7-14. doi: 10.11648/j.ijmfs.20180401.12

Received: May 14, 2017; Accepted: June 14, 2017; Published: May 17, 2018

\begin{abstract}
In this paper a hierarchical risk breakdown structure representation is used to develop qualitative risk assessment in a IPMA project. A common language for describing risks so as to achieve consistent quantification likelihoods and impacts is presented. The relationships between risks and their consequences are represented. These diagrams and the concepts of Fuzzy Delphi method are applied to identify relationships between risks and consequences on project performance measures. A methodology based on IPMA Competence Baseline (ICB) standards and Fuzzy Delphi developed by the International Project Management Association's (IPMA) and the project management baseline (pmb) is described. Following a similar approach, a relative small, low budget and non-complex photovoltaic power plant, presenting an actual case study of the installation of a 10 $\mathrm{kW}$, roof-top, integrated photovoltaic system, for domestic use, in a residence building in the region of East Attica, Greece is presented. At first, a brief description of the system of the project is summarized, including general information and basic technical characteristics. Next, the basic project planning documents, in the form of tables or charts, are deployed, taking into account the sequence they follow and the interrelationships between them. Finally, general conclusions regarding the whole process are stated.
\end{abstract}

Keywords: Fuzzy Logic. Fuzzy Delphi, Risk Assessment, Project Management Standards, IPMA Competence Baseline, Project Management Baseline, Photovoltaic Systems

\section{Introduction}

Systemic project risk management has an effect on a project's success. It has been found that there is a strong relationship between the amount of risk management efforts undertaken in a project and the level of the project's success [1]. Several project risk management approaches have been proposed [2-4]. Existing approaches may be summarized as a four-phase process for effective project risk management, i.e., identifying, assessing, responding, and monitoring and/or reviewing risks. Identifying risks is the first step which determines which risk components may adversely affect which project objectives and documents their characteristics [5]. Construction risks are classified in many ways by risk types (i.e., natures and magnitudes, etc.), the sources and/or origins, or the project phase [6-7]. Some present-day researchers propose a hierarchical structure of risks, which classifies risks according to their origin and the location at which the risk impacts on the project [8-9].

Assessing risks is a step which prioritizes the risks for further analysis by quantifying their occurrence rates. The risk assessment method is an essential component of this step. The existing methods are classified into simple classical methods, and advanced mathematical models [5]. The simple classical methods integrate deterministic risk modelling and analysis into CPM scheduling.

After Zadeh [10] introduced the concept of fuzzy sets and theory, researchers such as [4] and [5] introduced the fuzzy theory-based risk analysis as a part of a construction project risk management system which consists of five steps (i.e., risk identification, policy definition, risk sharing and allocation, risk analysis, and risk minimization and response planning, etc). The fourth component, risk analysis, consists of the following three steps: natural language computation, fuzzy set risk evaluation, and 
linguistic approximation.

In this paper we classify risks using a hierarchical risk breakdown structure in every aspect of life cycle analysis (design, management construction etc.) according to IPMA standards. It allows risks to be separated into those that are related to the management of each stage (i.e. design construction management phase).

It was based on questionnaires respondents to indicate the significance (importance) of each indicated risk factor. The questionnaire was conducted from April 2016 - October 2016 among clients, designers, general contractors, subcontractors and suppliers of building materials

\section{Fuzzy Set Theory}

Fuzzy set theory is a useful tool for dealing with multi-criteria decision-making taking into account uncertainty in the interpretation of alternatives [10]. In the conventional procurement cases of uncertain and dynamic environments, strategic planning is becoming even more important since strategic decisions could seriously impact the financial performance and status of a firm. Added to that is the common case of decision makers having to apply and evaluate a range of vague and sometimes conflicting criteria. In these cases managers find it much easier to express their opinions in linguistic terms (i.e. to differentiate between "high", "medium" and "low") rather than using numbers to measure an ambiguous event. However, linguistic variables contain ambiguity and multiplicity of meanings. Therefore, the information obtained can be expressed as fuzzy numbers, instead of a single value in traditional deterministic methods, thus z set, " 1 " describes a fully included member. Hence, for the universe $\mathrm{U}$ a fuzzy set $\mathrm{A}$ is defined as:

\subsection{The Fuzzy Delphi Method (FDM)}

The success of the Delphi method depends principally on careful selection of the panel of experts Cabaniss [11] suggested organizations, holding office in professional organization, presenter at national conventions, published in recognized journals"

The Fuzzy Delphi Method (FDM) consists of the following steps [12]

Step 1. The experts Ei $(i=1,2, \ldots ., n)$ are asked to provide their estimates (or appraisal) on the particular subject, determining the minimum $\alpha 1$ (i), the most plausible $\alpha \mathrm{M}(\mathrm{i})$ and the maximum $\alpha 2$ (i) values for these appraisals. The data given by the experts Ei are presented in the form of triangular numbers

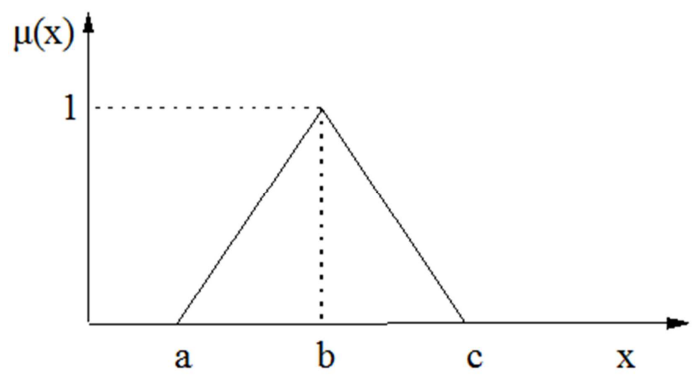

Figure 1. Membership function $\mu$ of a triangular fuzzy number.

$$
\mathrm{A}_{\mathrm{i}}=\left(\alpha_{1}{ }^{(\mathrm{i})}, \alpha_{\mathrm{M}}{ }^{(\mathrm{i})}, \alpha_{2}{ }^{(\mathrm{i})}\right), \mathrm{i}=1,2, \ldots, \mathrm{n}
$$

Step 2. The fuzzy average $A_{\text {avg }}=(\mathrm{m} 1, \mathrm{mM}, \mathrm{m} 2)$ of all $\mathrm{Ai}$ is estimated according to the equation:

$$
\mathrm{A}_{\mathrm{avg}}=\left(\mathrm{m}_{1}, \mathrm{~m}_{\mathrm{M}}, \mathrm{m}_{2}\right)=\left(\frac{1}{n} \sum_{i=1}^{n} a_{1}{ }^{(i)}, \frac{1}{n} \sum_{i=1}^{n} a_{m}{ }^{(i)}, \frac{1}{n} \sum_{i=1}^{n} a_{2}{ }^{(i)}\right)
$$

Next, for each expert the deviation between $\mathrm{A}_{\text {avg }}$ and $\mathrm{Ai}$ is computed, which is also a triangularly distributed number defined by:

$$
\text { Aave }-\mathrm{Ai}=(\mathrm{m} 1-\alpha 1(\mathrm{i}), \mathrm{mM}-\alpha \mathrm{M}(\mathrm{i}), \mathrm{m} 2-\alpha 2(\mathrm{i}))=\left(\frac{1}{n} \sum_{i=1}^{n} a_{1}{ }^{(i)}-a_{1}{ }^{(i)}, \frac{1}{n} \sum_{i=1}^{n} a_{m}{ }^{(i)}-a_{m}{ }^{(i)}, \frac{1}{n} \sum_{i=1}^{n} a_{2}{ }^{(i)}-a_{2}{ }^{(i)}\right)
$$

The deviation $A_{\text {avg }}-A_{i}$ is given back to the experts for revision.

Step 3. Each expert Ei gives a new triangular number

$$
\mathrm{B}_{\mathrm{i}}=\left(\mathrm{b}_{1}{ }^{(\mathrm{i})}, \mathrm{b}_{\mathrm{M}}{ }^{(\mathrm{i})}, \mathrm{b}_{2}{ }^{(\mathrm{i})}\right), \mathrm{i}=1,2, \ldots, \mathrm{n}
$$

The process defined by steps 2 and 3 is repeated until two successive means become, according to the decision makers, reasonably close.

\subsection{Aggregation of Fuzzy Numbers to Obtain the Fuzzy Attractiveness Rating (FAR)}

The merit ratings are expressed in linguistic terms, which are then translated into appropriate fuzzy numbers and aggregated into a single fuzzy number called the fuzzy attractiveness rating (FAR) associated with consequences [12] A higher SGF represents a stronger preference for the given bid opportunity. FAR is calculated using the following equation

$$
\mathrm{FAR}=\sum_{j=1}^{n} w_{j} R_{j} / \sum_{j=1}^{n} w_{j}
$$

where wj are the criteria weights, $\mathrm{Rj}$ are the (homogenous) ratings and $j(=1, \ldots, n)$ is the number of alternatives.

The fuzzy weights for the three boundary conditions of the underlying triangular distribution (low, medium, high) are obtained by use of the geometric mean and Eq. 2: 


$$
W_{t}=\left\{\min _{j}\left(W_{j t}\right),\left[\prod_{j=1}^{n}\left(W_{j t}\right)\right]^{1 / n}, \max _{j}\left(W_{j t}\right)\right\}
$$

where, $\mathrm{W}_{\mathrm{t}}$ is the fuzzy weight under criterion $\mathrm{t}$ and are decision makers. Both the fuzzy ratings and the fuzzy weights are normalized (divided by the number of choices and the number of experts-respondents respectively) so that the calculated numbers are in the range $0-1$.

The computed FAR number is translated back into linguistic terms ("defuzzified") and the decision is finally expressed in generally understandable linguistic terms represents the consequences. [13]

\section{IPMA Standards}

The most applied and wide spread IPMA Standard is the IPMA Competence Baseline (ICB) [14], a common framework document developed in the 90 s to ensure that consistent and harmonized standards are applied when handling with projects and programs. It provides the foundation for pm learning and development, as well as the official definition of the competences expected from pm professionals for their certification using the universal IPMA four-level certification system (http://ipma.ch/resources/ipma-publications) [14]. ICB, in its current third version (Version 3.0) edited in June 2006, uses the "eye of competence" as an appropriate symbol, representing the integration of all the elements of pm as seen through the eyes of the professional specialist who plans and controls a project, the project manager. Besides his indispensable technical competence, behavioural competences such as motivation and leadership are also essential, as well as dealing successfully with the organizational, economic and social context of the project. ICB groups a total of $46 \mathrm{pm}$ competence elements in three ranges: the technical range, covering the pm content with 20 technical elements, the behavioural range, covering the project manager's attitudes and skills with 15 behavioural elements, and the contextual range, covering the project manager's competence in managing relations with the line management organization with 11 contextual elements [14].

Project management baseline (pmb), the official standard of the Austrian pm IPMA associate (i.e. Projekt Management Austria), was first issued in 1999 and is already running its fifth update since 2009 (Version 3.0), constituting a useful manual of relevant knowledge elements, structured by definitions and process descriptions. It offers a consistently documented approach and ensures the consistent use of pm terminology, structured in three major chapters, in accordance with the three ranges of competence of the ICB Version 3.0: i) [13] an overview of the basic methods for the pm technical competences, structured by the pm sub-processes in which they are predominantly used; ii) a selection of the key elements of behavioural competences, focusing on the social competences, which are defined as the potential of a person in a role to act in a cooperative and self-organized way and iii) ways and means of managing project-oriented organizations, describing their model and specific features and presenting the most significant key elements of the pm context competences [14] Pmb emphasizes in the course of planning and preparing the various project plans, illustrating the interrelationships between the central pm methods that must be considered. [14]

\section{Phases of a Contruction Project}

In order to demonstrate the use of the method in the described process as related to construction projects, an illustrative example concerning photovoltaic is presented. Photovoltaics (PV) plants that convert solar radiation into direct current electricity due to growing demand for renewable energy sources in green buildings [15] are one of the most important projects in green building construction in $\mathrm{n}$ Greece. Their construction is subject to building codes and energy policy measures the main purpose of their use is to protect public health safety and general welfare. Usually in Greece the well-known design build system is the construction delivery system to the owner. The design builder is the usual general contractor used to minimize the project risk for the owner and reduce the delivery schedule by reducing the overlapping the design and construction phase of the project. In this case Professional project management (hereafter pm) requires rigorous standards and guidelines in order to define the work of the involved personnel. Standards provide high-level description of concepts and processes that are considered to form good practice in $\mathrm{pm}$. A standard is a document, issued by a recognized organization or institution, providing rules, guidelines or characteristics for the achievement of the optimum degree of order, in a given context [16-17]. Project Management Institute (PMI) and International Project Management Association (IPMA) are two of the world's leading non-profit, professional membership, associations for pm, that develop and apply such standards in order to improve project success. [18] The aim of the present paper is to demonstrate the process of managing the project of the installation of a photovoltaic (PV) power plant, according to the IPMA standards. The whole procedure is described through an actual case study of the design and construction of a small, integrated PV system, for domestic exploitation.

\subsection{Project Description}

Photovoltaic process is the direct conversion of sunlight to electricity and an attractive alternative to conventional sources of electricity supply. In simple words, a PV system is a complete set of interconnected components for converting sunlight into electricity power, consisting of a PV array, a balance-of-system and a load. As stated before, the project involves the planning, design and construction of a $10 \mathrm{~kW}$, roof-top, integrated, self-mounted, PV system. The PV plant was installed in a flat-roof of a single-house building of average energy requirements, in the region of East Attica, Greece, meant to be used for domestic exploitation. The project was carried out by a private technical construction company, on behalf of an individual, who was the owner and 
resident of the building. The general information of the project, as well as the main technical features of the basic system components, is summarized in Table 2, cited in the next page [19-21].

Table 1. Project Description

\begin{tabular}{|c|c|c|c|}
\hline \multicolumn{2}{|c|}{ General information } & \multicolumn{2}{|l|}{ Technical features } \\
\hline Title & Instalation of a $10 \mathrm{~kW}$, roof-top, PV system & PV array & 42 solar modules \\
\hline Owner & Individual & \multirow{2}{*}{ PV modules } & \multirow{2}{*}{ SCHUCO MPE $235 \mathrm{~W}$ ( 60 solar cells) in the PS 04 series } \\
\hline Location & Single-house in East Attica Region, Greece & & \\
\hline Designer & ErgoDesign Technical Company & Solar cells & polycristalline; $16,7 \%$ cell efficiency \\
\hline Contsructor & Ergo Green Energy E.E. & \multirow{2}{*}{ Inverters } & FRONIUS IG PLUS: $120 \mathrm{~V}-3$, three phase, nominal output \\
\hline Financing & Self funds & & $10.0 \mathrm{~kW}$ \\
\hline Duration & $\approx 3,5$ months & Electrical instalation & ABB GEMINI, solar cables $6 \mathrm{~mm}^{2}$ \\
\hline
\end{tabular}

The first step in the course of the project is to define the project scope and context by setting the project's objectives. They should clarify the meaning of the project and describe the desired results at its completion, and can be broken down into main, additional and non-objectives. The project objectives are listed in the Project Objectives Plan, presented in the following Table 3.

Table 2. Project Objectives Plan.

\begin{tabular}{ll}
\hline Objective type & Objective description \\
\hline Main Objectives & 1. Elecrical power cost reduction \\
& 2. Contribution on carbon dioxide $\left(\mathrm{CO}_{2}\right)$ emissions reduction \\
3. Potential for future full energy autonomy & 1. Minimization of optical irritation from equipment installation \\
Additional Objectives & 2. Site's area optimization for alterate usage of the flat - roof \\
& 3. Maximization of energy supply performance with the use of proper equipment \\
Non-Objectives & 1. Equipment maintenance after project completion \\
\hline
\end{tabular}

The analysis of the project environment is a process of determining and evaluating the relationships and influences of various "relevant" internal and external social environments on the project. These relationships have been assessed and characterized as positive, negative or neutral, using the symbols $(+),(-)$, or $( \pm)$ respectively. Figure 2, cited in the next page, depict the Project Environment Diagram, which represents schematically the influences of the different internal and external environments on the project.

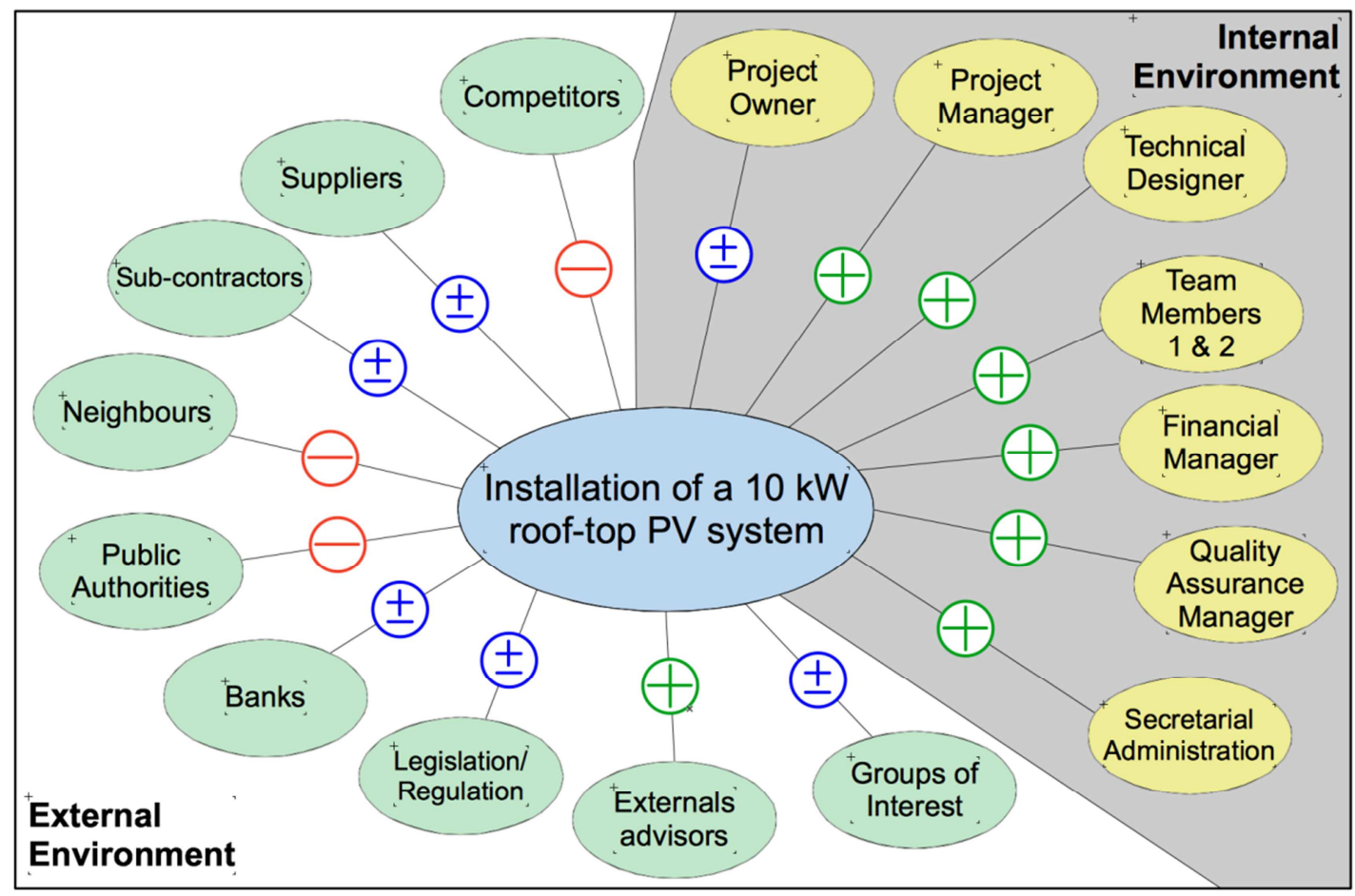

Figure 2. Project Environment Diagram. 


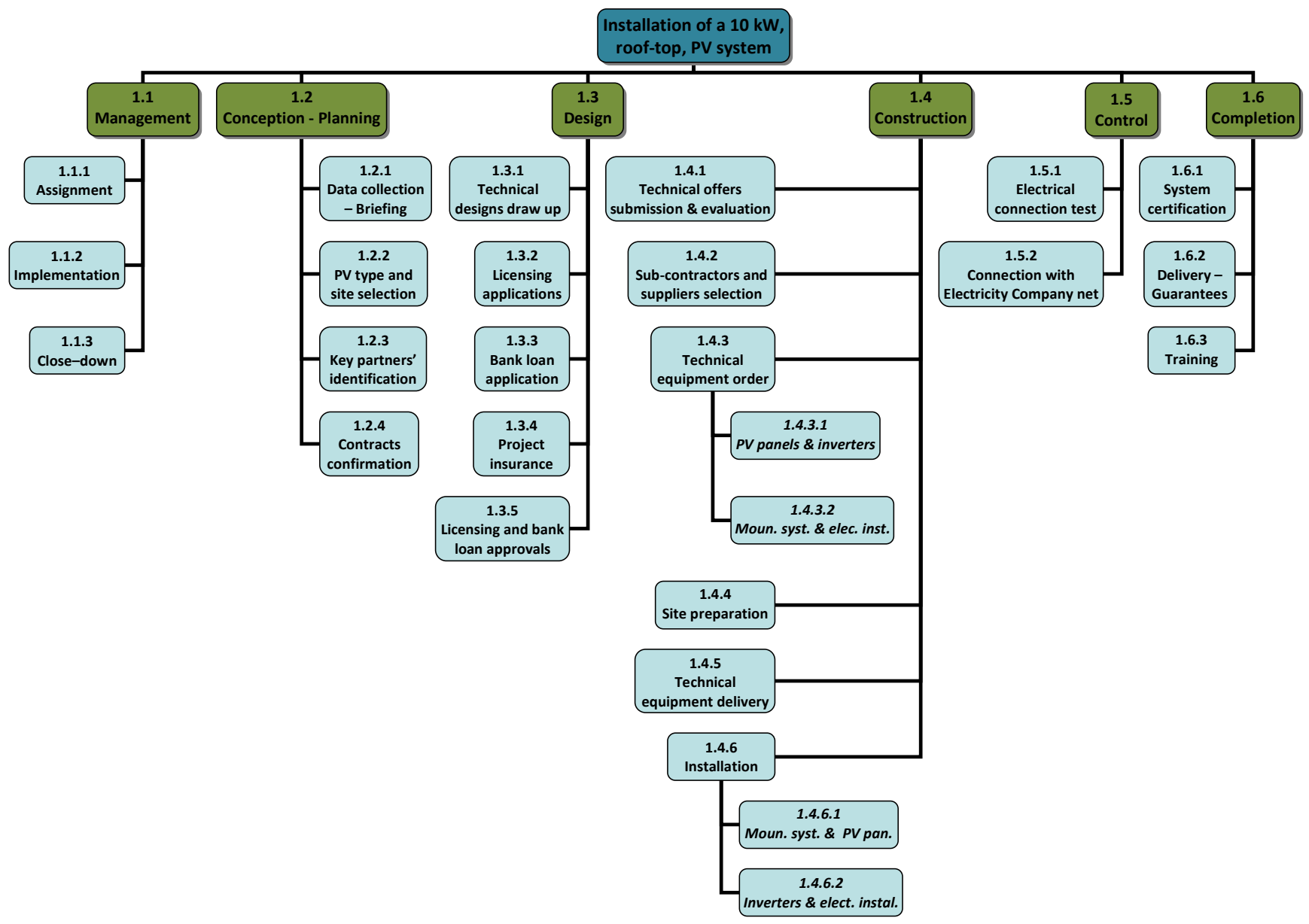

Work Breakdown Structure (WBS) represents a classification of all the tasks to be performed in the project into work packages that can be planed and managed, displayed as a tree diagram. The project's WBS is structured into four levels, where the first two of them represent the entire project and the main execution phases respectively, while the third and fourth one analyse the work packages in each one of the phases. In the proposed WBS, management throughout the whole project, although not constituting a separate task in the project execution, is displayed as an autonomous project phase, in order to be included and considered in the cost analysis of the project and in the formulation of the final project budget. Figure 3 presents schematically the tree diagram of the Project WBS.

\subsection{Photovoltaic Projects Phases}

\subsubsection{Project Inception Stage}

The purpose of the Project Inception Stage is:

i. to provide a forum for vetting proposals for photovoltaic Projects ensure that they are in keeping with portfolio strategies and investment plan; and,

ii. to review proposed projects that represent an opportunity which may not have been previously identified on any existing plan, or projects that may be characterized as high profile due to potential risk.

\subsubsection{Definition Phase}

The first phase of the project, Definition Phase, assesses the proposed project or opportunity to ensure that the proposal responds to an established set a criteria that result in a go/no-go decision.

\subsubsection{Project Identification Stage}

The purpose of the Identification Stage is:

i. To ensure that a project submitted for preliminary approval has been adequately assessed and analysed within the context of the Program and represents the best investment solution.

ii. To assist clients in identifying and developing the most appropriate projects for their departmental objectives and in support of the government agenda for Photovoltaics.

\subsubsection{Initiation Phase}

The Initiation Phase identifies the need or opportunity and provides an initial description of goals, objectives, requirements and related issues sufficient to allow for a preliminary assessment on the merit and suitability of the project.

\subsubsection{Feasibility Phase}

The business requirements are finalized in the Feasibility 
Phase. Information is also provided to evaluate the range of solutions meeting the project requirements.

\subsubsection{Analysis Phase}

The purpose of the Analysis Phase is to substantiate the optimum solution that will satisfy the project requirements and constraints. This phase will also establish the project budget, schedule, controls, and evaluation criteria that will be put forward for preliminary project approval.

\subsubsection{Identification Close out Phase}

The Identification Close Out Phase finalizes the project management activities required to complete the project Identification Stage.

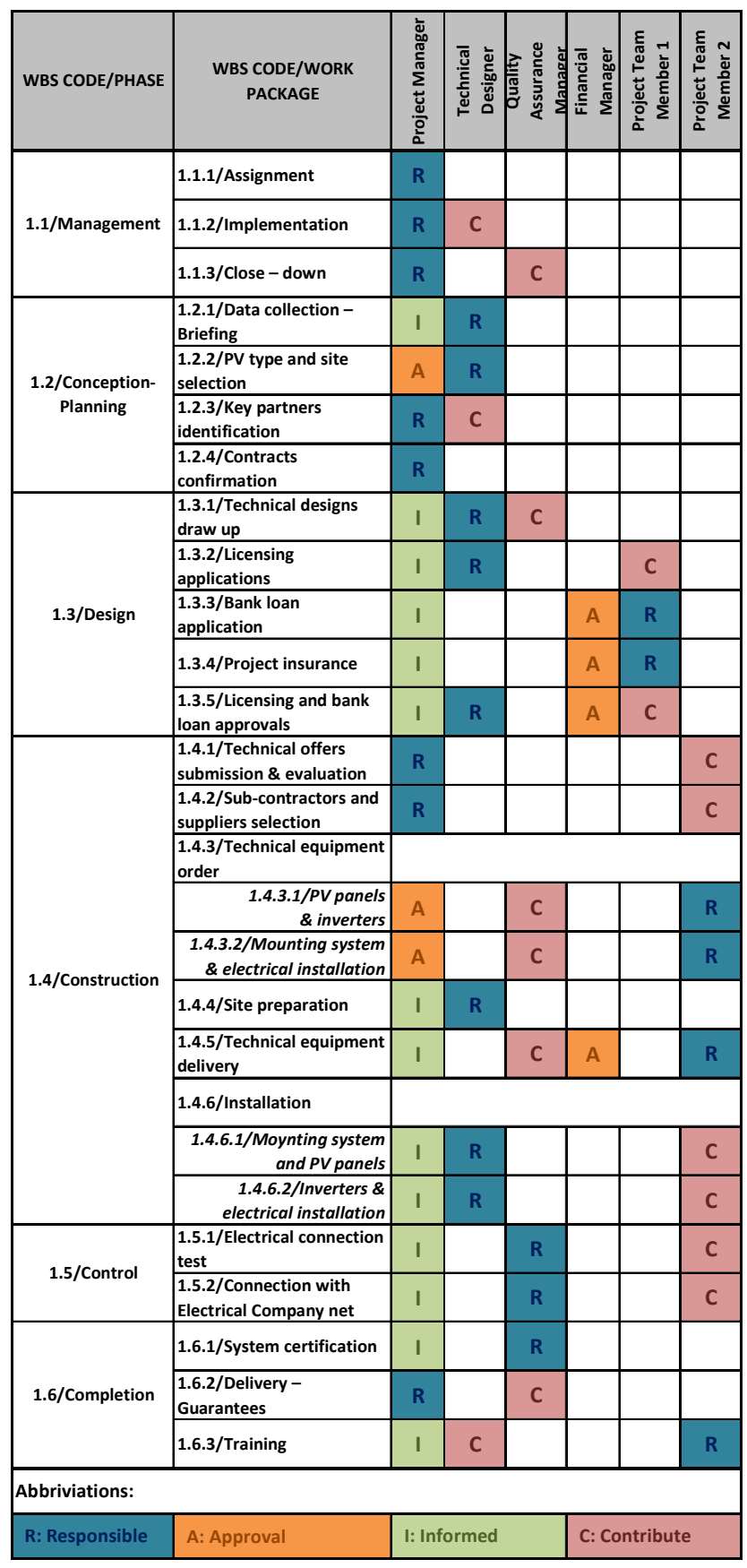

Figure 4. Project Responsibility Matrix.

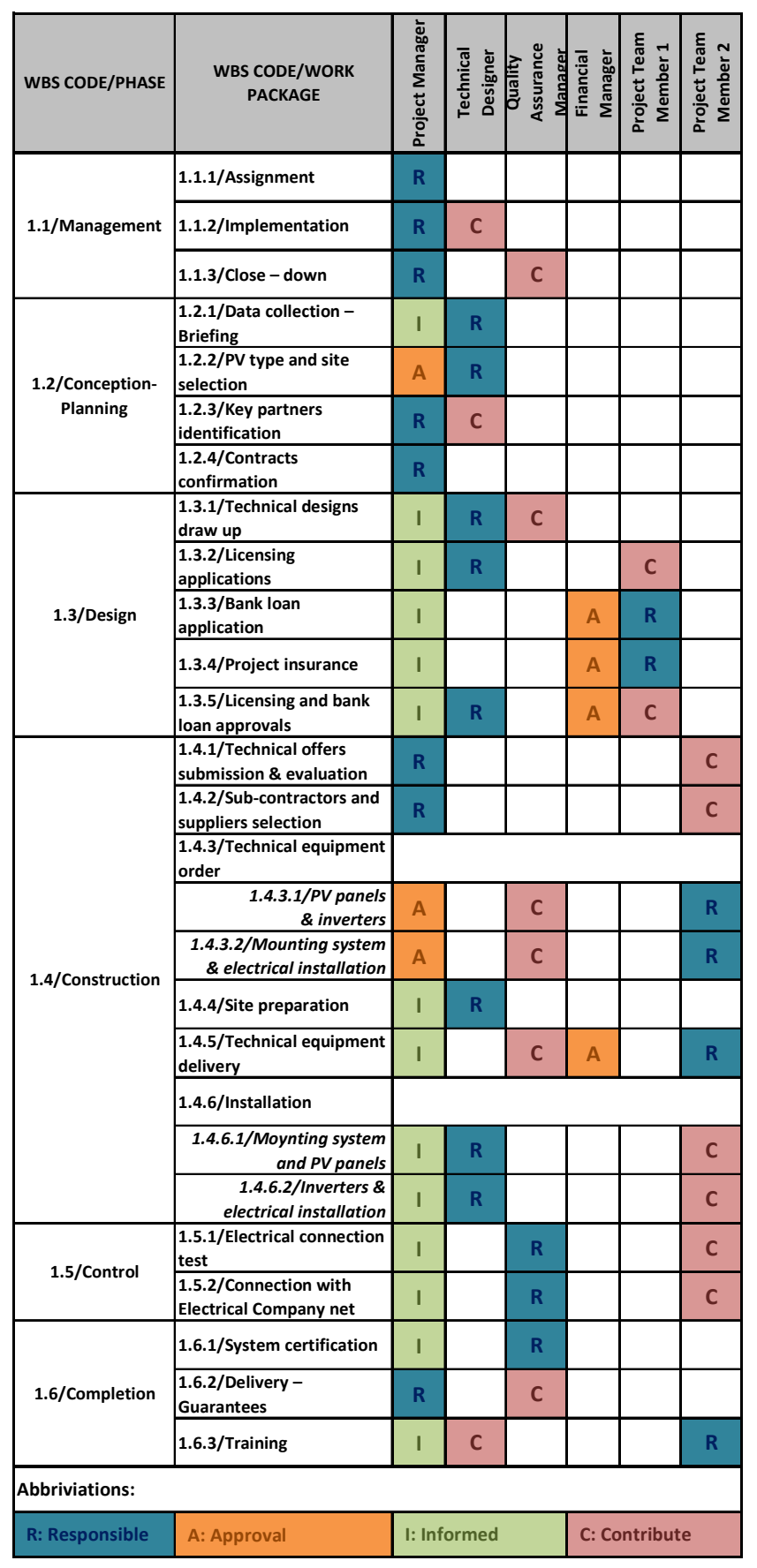

Figure 5. Organization Description plan.

\subsubsection{Project Delivery Stage-Conception Planning Phase}

The Project Delivery Stage translates the approved project objectives and requirements into technical criteria to allow for detailed design, development and full implementation of the end product, service or result at an acceptable level of quality to meet client and stakeholder requirements.

The Planning Phase Initiates project start-up activities and ensures that the project objectives and requirements provide sufficient detail to allow for the preparation of complete project instructions to the project team.

\subsubsection{Design Phase}

The Design Phase establishes the project team and develops 
a design complying with the project objectives and requirements. The approval documents are also produced for effective project approval.

\subsubsection{Construction Phase and Control Completion Phase}

During the Construction Phase the approved design is converted into a solution that meets the project objectives and requirements. The product is also released to operations in accordance with branch/departmental service management processes and standards.

The control phase is the control of building codes and energy policy measures the main purpose of their use is to protect public health safety and general welfare. The Completion Phase completes the project management activities related to the delivery stage and provides an assessment of project performance against the project objectives and requirements.

Note: for the purposes of maintaining and operating the delivered product, a control phase must either be produced or an existing agreement must be amended to ensure that the product and services produced by the project are supported subsequent to project close-out.

\section{Risk Analysis}

Data from 43 questionnaires was collected, then analysed to determine the degree of significance of each risk factor, taking their impact on the execution parameters of the construction project into account. In this paper, the authors present only a part of the survey results concerning the influence of chosen factors on the duration and cost of the construction project execution. In this regard, each respondent was asked to characterize Low (L), Medium (M), High (H), and very High (VH).

After collecting and analysing the data from the questionnaires, the degree of significance for each factor was determined. The results are given in Figures 5 and 6.

The risk analysis process comprises the stages of risk identification, risk assessment and risk evaluation. Risk assessment is defined as the likelihood of various events occurring, combined with the impact of these events on the project [11], mainly on time and cost increase, and can be reported in a Risk Assessment Table. Due to space limitation, the Risk Assessment Table of the project, presented in Table 5 in the next page, reports only a number of the identified project risks. Risk evaluation is conducted by comparing the significant risks R2-R18 assessed with a tolerable risk level, presented in the Risk Evaluation Matrix. If the expected risk value is greater than the tolerable level of risk, then preventive risk response measures must be taken. Figure 7, cited also in the next page, presents the Risk Evaluation Matrix of the project.

\begin{tabular}{|c|c|c|c|c|c|c|}
\hline \multirow{2}{*}{$\begin{array}{l}\text { WBS CODE/ } \\
\text { PHASE }\end{array}$} & \multicolumn{2}{|r|}{ RISK } & \multirow{2}{*}{ 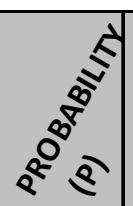 } & \multirow{2}{*}{ 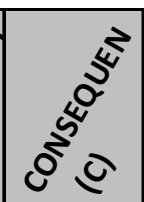 } & \multirow{2}{*}{ 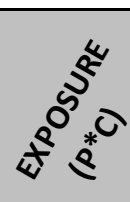 } & \multirow{2}{*}{$\int^{5^{5}}$} \\
\hline & CODE & DESCRIPTION & & & & \\
\hline \multirow{3}{*}{$\begin{array}{c}1.1 / \\
\text { Management }\end{array}$} & $\mathbf{R}_{2}$ & Poor project management & $10 \%$ & 0,80 & 0,08 & $\mathbf{F}_{3}$ \\
\hline & $\mathbf{R}_{\mathbf{4}}$ & Taxation and legislation restrictions & $50 \%$ & 0,40 & 0,20 & $F_{4}$ \\
\hline & $\mathbf{R}_{\mathbf{5}}$ & Poor risk management & $30 \%$ & 0,80 & 0,24 & $\mathbf{F}_{3}$ \\
\hline \multirow{2}{*}{$\begin{array}{l}\text { 1.2/Conceptio } \\
\text { n Planning }\end{array}$} & $\mathbf{R}_{\mathbf{8}}$ & Inappropriate data collection & $30 \%$ & 0,40 & 0,12 & $F_{1}$ \\
\hline & $\mathbf{R}_{\mathbf{9}}$ & Deficient partners identification & $10 \%$ & 0,80 & 0,08 & $\mathbf{F}_{1}$ \\
\hline 1.3/Design & $\mathbf{R}_{11}$ & Late licencing approvals & $50 \%$ & 0,40 & 0,20 & $\mathbf{F}_{4}$ \\
\hline \multirow{4}{*}{$\begin{array}{l}1.4 / \\
\text { Construction }\end{array}$} & $\mathbf{R}_{12}$ & Natural hazards/disasters & $10 \%$ & 0,40 & 0,04 & $\mathbf{F}_{2}$ \\
\hline & $\mathbf{R}_{15}$ & Delay on equipment delivery & $30 \%$ & 0,40 & 0,12 & $\overline{F_{1}}$ \\
\hline & $\mathbf{R}_{16}$ & Labour accident & $10 \%$ & 0,40 & 0,04 & $\overline{F_{1}}$ \\
\hline & $\mathbf{R}_{\mathbf{1 7}}$ & Reactions from neighbors or inhabitants & $10 \%$ & 0,20 & 0,02 & $F_{1}$ \\
\hline 1.5/ Control & $\mathbf{R}_{18}$ & $\begin{array}{l}\text { Late authorization from Electricity Company } \\
\text { and connection with the net }\end{array}$ & $50 \%$ & 0,40 & 0,20 & $\mathbf{F}_{4}$ \\
\hline \multicolumn{6}{|c|}{ Response actions annotation } & \\
\hline \multicolumn{2}{|c|}{$\begin{array}{l}\mathrm{F}_{1}: \text { Risk elimination with } \\
\text { precaution measures }\end{array}$} & \begin{tabular}{|l|l|}
$F_{2}:$ Risk diversion and & $F_{3}:$ Mitigation of risk \\
shifting to other parts & likelihoood/consequen
\end{tabular} & \multicolumn{3}{|c|}{$\begin{array}{l}\mathrm{F}_{4}: \text { Risk acception } \\
\text { undertaking cost }\end{array}$} & \\
\hline
\end{tabular}

Figure 6. Risk Assessment Table. 


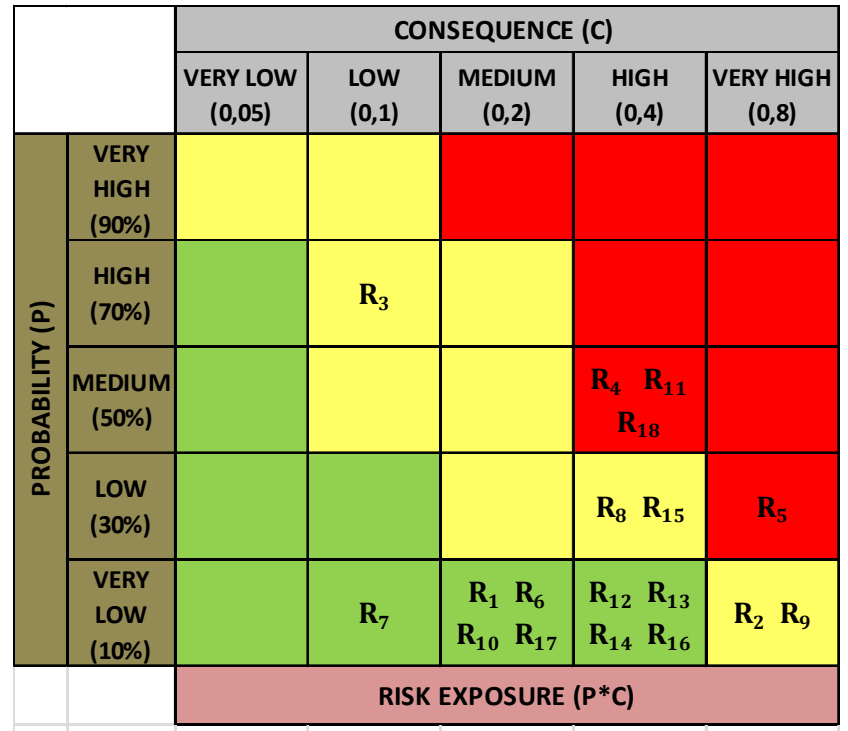

LOW EXPOSURE

MEDIUM EXPOSURE HIGH EXPOSURE

Figure 7. Risk Evaluation Matrix.

\section{Conclusions}

A hierarchical risk breakdown structure is developed to facilitate risk identification. A common language developed for describing risks and impacts so to achieve quantification is presented. The relationships between risk and their FAR and associated consequences are represented. The concepts of fuzzy association and fuzzy composition are applied to identify relationships between risks and the consequences on projects performance measures. A methodology for evaluating risk exposures considering consequences in terms of cost time and quality is presented.

\section{References}

[1] Elkington, P., and Smallman, C. (2002). Managing project risks: A case study from the utilities sector. International Journal of Project Management, 20, 49-57.

[2] Chapman, C., (1997). Project risk analysis and management the PRAM generic process, International Journal of Project Management, 15, 273-281.

[3] An M., Baker C., and Zeng, J., (2005), A Fuzzy Logic-Based Approach to Qualitative Risk Modeling in the Construction Process, World Journal of Engineering, 2, 1-2. M.

[4] $\mathrm{PMBOK}{ }^{\circledR}$ Guide and Standards https://www.pmi.org/pmbok-guide-standards.

[5] Nieto-Morote, A., Ruz-Vila, F., (2011). A fuzzy approach to construction project risk assessment, International Journal of Project Management, 29, 220-23.
[6] KarimiAzari, et al. (2011). Risk assessment model selection in construction industry, Expert Systems with Applications, 38, 9105-9111.

[7] Bannerman, P. L. (2008). Risk and risk management in software projects: A reassessment. The Journal of Systems and Software, 81(12), 2118-2133.

[8] Cooper, D. F., Champan, C. B., (1987). Risk Analysis for a Large Project. Wiley, Chichester.

[9] Klemetti, A. (2006). Risk management in construction project networks. Report 2006/2. Finland: Laboratory of Industrial Management, Helsinki University of Technology.

[10] Tah, J. H. M., Thorpe, A., McCaffer, R.,(1993). Contactor project risks contingency allocation using linguistic approximation. Computing System in Engineering, 4, 281293.

[11] Wirba, E. N., Tah, J. H. M., Howes, R., (1996). Risk interdependencies and natural language computations. Journal of Engineering, Construction and Architectural Management, 3, 251-269.

[12] Zadeh, L. A., (1965). Fuzzy sets. Information Control 8, 338 353.

[13] Cabaniss, K. (2001) Counseling and computer technology in the new millennium - an internet Delphi study, Ph.D dissertation, Virginia Polytechnic Institute and State University, Virginia, U.S.A. Wireless LAN Medium Access Control (MAC) and Physical Layer (PHY) Specification, IEEE Std. 802.11, 1997.

[14] O. G. Manoliadis, J. P. Pantouvakis, S. E. Christodoulou, Improving qualifications-based selection by use of the fuzzy Delphi method, Construction Management and Economics, 27, 4, 373-384, 2009.

[15] ICB - IPMA Competence Baseline, Version 3.0 (2006). Nijkerk: IPMA Standards of IPMA World v.4 http://www.ipma.world/resources/standards/

[16] https://en.wikipedia.org/wiki/Photovoltaics.

[17] Petridis, D. P. (2014). Design and construction of an integrated photovoltaic system into a residence, with the IPMA management method (in Greek) (M.Sc. Thesis). Open University of Athens.

[18] Gareis, R. (2006). Happy Projects! (in German), 3rd Edition, Manz Verlag.

[19] Lock, D. (2013). Project Management, 10th Edition, Gower Publishing Limited, U.K

[20] Pantouvakis, J. P. (2013). Project Management with IPMA standards (in Greek), Athens. Hellenic Open University, Patra, Greece.

[21] Reyes, J. and Almela J. M. (2006). Processes in Projects and Project Management Competences (in Spanish). Confirmation of revised paper submitted. 